\title{
Research on the Spatial Correlation of Regional Economic Growth in Guangdong Province - Based on Analytic Network Process
}

\author{
Min $\mathrm{LI}^{1, \mathrm{a}}$, Zi-ting $\mathrm{LI}^{1}$, Zheng-qun $\mathrm{ZHAN}^{1, \mathrm{~b}, *}$ and Yan-ling SONG ${ }^{1}$ \\ ${ }^{1}$ School of Economics and Commerce, South China University of Technology, P.R. \\ China, 510004 \\ aLim@scut.edu.cn, ${ }^{\mathrm{b}}$ Zhanzq@scut.edu.cn \\ ${ }^{*}$ Corresponding Author
}

Keywords: Regional economic growth, Spatial correlation, Analytic network process.

\begin{abstract}
This paper collects the data of 20 cities' regional gross domestic product (GDP) in Guangdong from 1979 to 2013 as basic to measure the spatial correlation of regional economic growth between cities by establishing the VAR models and depicts the characteristics of spatial correlation of regional economic growth in Guangdong through the Analytic Network Process. The results show that: (1) There exist 160 spatial correlation relationships between cities and the spatial correlation is stability and multiple. After modularization, 20 cities can be divided into four modules--the bidirectional spillover module, net spillover module, main beneficial module and net beneficial module. The spillover network structure of economic growth has obvious flattening feature. (2) Guangzhou and Shenzhen are the engines of the spatial spillover of economic growth in Guangdong. Shanwei and Shaoguan are the main sources of the growth energy. (3) The Pearl River Delta influences the spatial spillover of regional economic growth in peripheral areas prominently. Within the Pearl River Delta, Dongguan is the main beneficiary in this spillover effect. And Zhaoqing belongs to the net beneficial module, so fails to play a role of transferring the growth energy to other cities. (4) The differences of industrial structure between cities will have a negative effect on spatial correlation. And the differences in the degree of openness between cities will promote the spillover effect of regional economic growth significantly.
\end{abstract}

\section{Introduction}

Since reform and opening up, Guangdong realized a pattern of opening from SEZ to coastal cities, then to PRD, and to the whole province finally. Firstly, Shenzhen, Zhuhai and Shantou were selected as SEZ in 1979 and further Guangzhou and Zhanjiang became the coastal opening cities in 1984. Secondly, PRD was developed as the opening zone of economic. Thirdly, the remaining mountainous area in the eastern and northern of Guangzhou was developed gradually. In the opening process from coastal cities to mountainous area, is there the spatial spillover effect of economic growth between cities in Guangdong? How is the characteristic and routes of this spillover effect? And which factors can influence the spillover effect? This paper will mainly focus on these three questions.

At present, the studies of regional economic growth in China are mainly concentrated on the factors analysis [1]. Research about spatial correlation of regional economic growth is gradually developed, but still not enough. These articles can be classified mainly according to following two aspects. (1) The scope of region. Part of literature about the spatial correlation 
in China analyze through dividing into several regions: Brun et al.(2002)studied the correlation between coastal areas and inland areas, and discussed whether the support policy of industrial development in coastal provinces led to the spillover effect of regional economic growth. Groenewold et al.(2007)mainly investigated the intensity, direction and market of spillover effect between the coastal area, midland and western area in China. And some domestic scholars researched on the economic development zone and non-economic development zone[8], or the typical eastern area, midland, western area and northeast area [7]. Furthermore, there are many papers that studied on the spatial correlation of economic growth between provinces [4-6,9]. (2) Research method. Spatial econometric model is frequently used to measure the regional correlation of economic growth through the establishment of the VAR models between each two regions[2,5]. And part of scholars judged and analyzed the correlation between regions by calculating Moran's I index [6].

According to the research of Lijing et al. (2014), this paper focus on the spillover effect of economic growth between 20 cities in Guangdong and collects the data of 20 cities' regional gross domestic product (GDP) from 1979 to 2013 as basic to measure the spatial correlation of regional economic growth between cities by establishing the VAR models. In addition, the Analytic Network Process is introduced in this paper. Through the construction of spatial correlation network and the analysis of modularization, article depicts the characteristics of spatial correlation of regional economic growth in Guangdong.

\section{The Spatial Correlation of Economic Growth between 20 Cities in Guangdong}

\section{The Establishment of VAR Models between Cities}

This paper mainly discusses the spatial correlation after reform and opening up in Guangdong. So the GDP of 20 cities (In this paper, the object of research is 20 cities, not including Jieyang. Jieyang was formally established in December 7th, 1991.) from 1979 to 2013 is used as basic data. We take 1979 as the base and calculate the constant GDP of cities every year in order to eliminate the influence of price level, and then get the natural logarithm of constant GDP to remove the time trend. The sequences of regional economic growth should be the stationary time series in order to avoid spurious regression before the establishment of the VAR models. And the ADF Test is needed to examine the stationary of the sequences of regional economic growth. The results show that GDP of cities are the second order stationary series at 5\% confidence level. So this article transforms all data into second order difference and establishes the VAR models between each two cities. We use LR, FRE, AIC, SC and HQ to identify the optimal lag periods of models and reconstruct the VAR models to conduct the Granger Causality Test at $1 \%$ significance level. Because the spillover of economic growth is directed, the maximum number of relation between 20 cities is 380 . The actual number of relation passed by test is 160 .

\section{The Construction of Correlation Network of Regional Economic Growth}

According to the test results of VAR models, this paper constructs the correlation matrix of regionaleconomic growth: the relations that can be confirmed are 1 and other relations are 0 . By using the network analysis tools - Ucinet, we get the correlation network of regional economic growth (Figure1), and depict the characteristics of network (Table 1,2).

In this paper, we depict the characteristics of spatial correlation network of regional economic growth by three indicators: The density of network is 0.421 . It implies these 20 cities 
are not so close in terms of economic cooperation. The connectedness of spatial correlation network is 0.684 . There is stability spillover effect in the network. And the efficiency of network is 0.351 , demonstrated that the network is multiple and has enough channels to spillover.

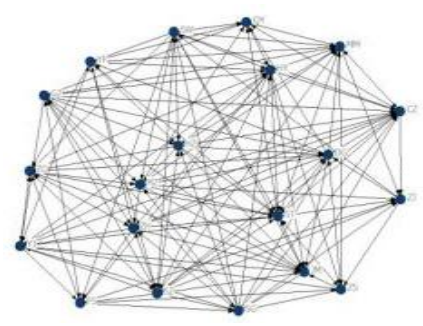

Figure 1. The Correlation Network of Regional Economic Growth between 20 Cities in Guangdong

Table 1. Network Characteristic Analysis

\begin{tabular}{c|l|l|c}
\hline Indicators & \multicolumn{1}{|c|}{ Content } & \multicolumn{1}{c|}{ Formula } & Value \\
\hline Density & $\begin{array}{l}\text { The density of correlation between } \\
\text { cities in the network. }\end{array}$ & $\begin{array}{l}\text { Dn=L/[N*(N-1)]; } \text { is the number of cities; } \mathrm{L} \\
\text { is the number of correlation actually. }\end{array}$ & 0.421 \\
\hline Connectedness & $\begin{array}{l}\text { The degree that cities can reach each } \\
\text { other in the network. }\end{array}$ & $\begin{array}{l}\mathrm{C}=1-\mathrm{V} /[\mathrm{N} *(\mathrm{~N}-1) / 2] \text { V is the number of pairs } \\
\text { that can't reach each other. }\end{array}$ & 0.684 \\
\hline Efficiency & $\begin{array}{l}\text { The degree of redundant edges } \\
\text { existence in the network. }\end{array}$ & $\begin{array}{l}\mathrm{GE}=1-\mathrm{M} / \max (\mathrm{M}) ; \mathrm{M} \text { is the number of } \\
\text { redundant edges; max }(\mathrm{M}) \text { is the maximum } \\
\text { number of redundant edges. }\end{array}$ & 0.351 \\
\hline
\end{tabular}

\section{The Modularization Analysis of Spatial Correlation Network}

Based on the spatial correlation matrix of regional economic growth, this research has the modularization analysis of the correlation between 20 cities in Guangdong by using Ucinet. We set the maximum depth of segmentation as 2, the convergence criteria as 0.2 and get four modules of economic growth (Figure 2). The first module includes the cities of Guangzhou, Foshan and Shaoguan, which mainly located in the active region of economic development. The second module contains the cities of Shenzhen, Huizhou, Shanwei, Zhongshan and Zhanjiang. All are the fast-developing regions which located in the coastal area. The third module includes the cities of Zhuhai, Heyuan, Meizhou, Dongguan, Jiangmen and Chaozhou. The forth module contains the cities of Shantou, Yangjiang, Maoming, Zhaoqing, Qingyuan and Yunfu, and most of these cities are located in the backward area of western in Guangdong. The GDP of Yunfu in 2014 was 66.4 billion yuan, ranked last in the 20 cities. And the GDP of Yangjiang and Qingyuan in 2014 are 116.855 billion yuan and 118.77 billion yuan, and ranked 14 and 13 in 20 cities respectively.

Analyzing the results of modularization further can obtain the routes of spillover effect between modules. We can get the density matrix between four modules of economic growth through Ucinet (Table 2). The density of whole network is 0.421 . If the density between modules is greater than 0.421 , it implies that the correlation between modules is significant [5]. So we set the value as 1 in density matrix that is greater than 0.421 , as 0 contrarily and have the image matrix (Table 2).

As shown in table 2, module 1, 3 and 4 all have reflexivity. There is significant spillover effect between cities in modules internally while the correlation between cities in module 2 is non-significant. Module 1 can drive the economic development of module 2 and 3 . Module 2 can transfer the energy of economic growth to module 1, 3 and 4 generally. Module 3 mainly transfers the energy of economic growth to module 4 . But the spillover of module 4 is 
non-significant and module 4 mainly plays a role of beneficiary in the process of spatial spillover in Guangdong.

Table 2. The Density/ Image Matrix of Four Modules

\begin{tabular}{c|c|c|c|c}
\hline & Module 1 & Module 2 & Module 3 & Module 4 \\
\hline Module 1 & $0.667 / 1$ & $0.467 / 1$ & $0.667 / 1$ & $0.167 / 0$ \\
\hline Module 2 & $0.467 / 1$ & $0.35 / 0$ & $0.5 / 1$ & $0.5 / 1$ \\
\hline Module 3 & $0.278 / 0$ & $0.233 / 0$ & $0.533 / 1$ & $0.694 / 1$ \\
\hline Module 4 & $0.167 / 0$ & $0.3 / 0$ & $0.306 / 0$ & $0.467 / 1$ \\
\hline
\end{tabular}

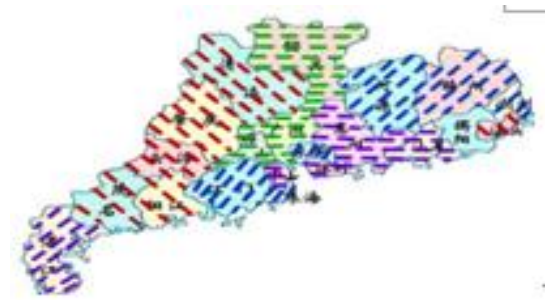

Figure 2. The Module Distribution(In 4 Colors)

In order to analyze the characteristics and position of modules, this research sets four roles of modules according to the study of Li Jing et al. (2014): Main beneficial module. This module mainly receives the energy of economic growth, but the spillover effect to other modules is non-significant. And the net beneficial module merely receives but has no spillover; Net spillover module. The relation between this module and other modules is denser than the relation between cities within this module. And it receives little energy from other modules; Bidirectional spillover module. Cities in this module transfer the energy of economic growth not only to cities in other modules, but also to cities within module. There is little receiving from other modules; Agent module. Cities receive from other modules and send to other modules at the same time. But the correlation between cities within the module is non-significant.

Wasserman and Faust (1994) developed a standard to evaluate the role of modules: We assume to analyze the correlation between members in module $\mathrm{B}_{\mathrm{k}}$. The number of actors is $\mathrm{g}_{\mathrm{k}}$, and the possible relation in $B_{k}$ is $g_{k}\left(g_{k}-1\right)$. And the number of whole sample is $g$, so the total possible relation of $B_{k}$ is $g_{k}(g-1)$. The relation expected ratio of $B_{k}$ is $\left(\mathrm{g}_{\mathrm{k}}\left(\mathrm{g}_{\mathrm{k}}-1\right)\right) /\left(\mathrm{g}_{\mathrm{k}}(\mathrm{g}-1)\right)=\left(\mathrm{g}_{\mathrm{k}}-1\right) /(\mathrm{g}-1)$. Combining this standard with the fact of modules of regional economic growth in Guangdong, the category of four modules can be obtained (Table $3)$.

Table 3. The Category of Modules

\begin{tabular}{c|c|c}
\hline \multirow{2}{*}{$\begin{array}{c}\text { The Proportion of Internal } \\
\text { Relations }\end{array}$} & \multicolumn{2}{|c}{ The Proportion of Relations that Received from other Modules } \\
\cline { 2 - 3 }$\geq\left(\mathrm{g}_{\mathrm{k}}-1\right) /(\mathrm{g}-1)$ & Bidirectional Spillover Module & $\begin{array}{c}\text { Main Beneficial Module/ Net } \\
\text { Beneficial Module }\end{array}$ \\
\hline$<\left(\mathrm{g}_{\mathrm{k}}-1\right) /(\mathrm{g}-1)$ & Net Spillover Module & Agent Module \\
\hline
\end{tabular}

Combining the analysis of modularization and the category, the characteristics of four economic modules are as follows (Table 4): The actual proportion of internal relation of module 1 is $15.38 \%$, greater than the expected proportion and has reflexivity. The number of relation from module 1 to other modules is 22 . Module 1 transfers the energy more not only to members within module, but also to members of other modules. But the receiving from outside 
is less and belongs to the bidirectional spillover module; the number of relation from module 2 is 44 . The actual proportion of internal relation is $15.91 \%$, and the network between members within module 2 is sparse. But the spillover from module 2 to other modules is dense and the receiving from other modules is less. Module 2 is the net spillover module; the number of relation from module 3 is 53, but is mainly composed of the internal relation. Module 3 has significant reflexivity and transfers the energy of economic growth to other modules less. But the receiving from outside is more, module 3 belongs to the main beneficial module; six cities from module 4 have 37 relation of spillover and the actual proportion of internal relation is $37.84 \%$. The receiving from other modules is most and the transfer from module 4 is less. Module 4 is the net beneficial module.

Table 4. The Characteristic of Modules

\begin{tabular}{c|c|c|c|c|c|c|c|c|c|c}
\hline Modules & $\begin{array}{c}\text { Module 1 } \\
\text { Receiving }\end{array}$ & 2 & 3 & 4 & Members & $\begin{array}{c}\text { Expected Proportion } \\
\text { of Internal relation }\end{array}$ & $\begin{array}{c}\text { Actual Proportion } \\
\text { of Internal relation }\end{array}$ & $\begin{array}{c}\text { Receiving } \\
\text { in Total }\end{array}$ & $\begin{array}{c}\text { Spillover } \\
\text { in Total }\end{array}$ & Characteristic \\
\hline $\begin{array}{c}\text { Module 1 } \\
\text { Spillover }\end{array}$ & 4 & 7 & 12 & 3 & 3 & $10.53 \%$ & $15.38 \%$ & 15 & 26 & $\begin{array}{c}\text { Bidirectional } \\
\text { Spillover }\end{array}$ \\
\hline 2 & 7 & 7 & 15 & 15 & 5 & $21.05 \%$ & $15.91 \%$ & 23 & 44 & Net Spillover \\
\hline 3 & 5 & 7 & 16 & 25 & 6 & $26.32 \%$ & $30.19 \%$ & 38 & 53 & Main Beneficial \\
\hline 4 & 3 & 9 & 11 & 14 & 6 & $26.32 \%$ & $37.84 \%$ & 43 & 37 & Net Beneficial \\
\hline
\end{tabular}

Module 2 can transfer the energy of economic growth to module 1, 3 and 4 generally. Module 1 can drive the economic development of module 2 and 3. Module 1 and 2 are the main sources of the spillover effect of regional economic growth in Guangdong. In these two modules, Shenzhen, Shanwei, Guangzhou and Shaoguan all have high out-degree centrality. But in fact, the economic development of Shanwei and Shaoguan are weaker than Shenzhen and Guangzhou, the spillover capability of Shanwei and Shaoguan are weaker too. So Guangzhou and Shenzhen are engines of economic growth in Guangdong, Shanwei and Shaoguan are main senders of energy of economic growth. Module 3 mainly transfers the energy of economic growth to module 4 . But the spillover of module 4 is non-significant and module 4 plays a role of beneficiary in the process of spatial spillover in Guangdong. The Pearl River Delta influences the spatial spillover of regional economic growth in peripheral areas prominently. Zhaoqing belongs to the net beneficial module, so the spillover effect of economic is weak. The scale of the export processing trade industry in Dongguan is relative large. The orders of industry should depend on neighboring cities. So Dongguan is the main beneficiary in this spillover effect. The network structure of spatial correlation of economic growth in Guangdong has obvious flattening feature (Figure 3).

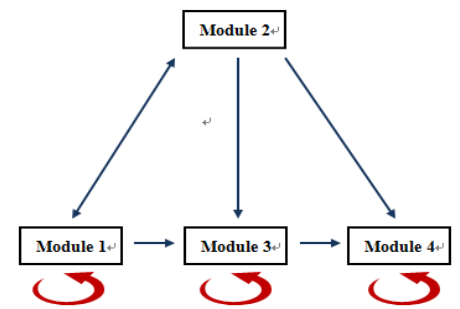

Figure 3. The Routes of Spillover between Modules 


\section{The Factors Analysis on the Spatial Correlation of Regional Economic Growth in Guangdong}

\section{Theoretical Hypothesis and Research Design}

According to existing research, the analysis of spatial correlation of regional economic growth mainly focus on the geographical proximity and the distinction of development between regions. Ying(2000), Pan Wenqing(2012) and LiJing et al. (2014) all believe the spatial correlation of economic growth between neighboring regions is more significant. Moreover, Groenewold et al. (2008) demonstrated that the development distinction between regions will influence the spatial correlation. The indicators ---- the construction of investment and consumption, the degree of economic openness, industrial structure, employment structure and the movement of human capital, are the possible factors to influence the spillover effect [5-6]. In the consideration of the fact and the data availability, this paper improves the indicators and develops the theoretical hypothesis: the spatial correlation $\mathrm{R}$ of economic growth between cities in Guangdong is affected by five factors, including the neighborhood relation $\mathrm{S}$ in spatial, the distinction of GDP proportion I of the secondary industry and the tertiary industry, the distinction of proportion $\mathbf{J}$ of the total wages of employees and the GDP, the distinction of proportion $\mathrm{K}$ of the fixed investments and the GDP, the distinction of proportion $\mathrm{O}$ of the total import- export value and the GDP.

The dependent variable $\mathrm{R}$ of the spatial correlation of regional economic growth can be obtained from the spatial correlation matrix above. The $\mathrm{S}$ can be shown as the matrix of spatial neighborhood, we set 1 if it is neighboring between two cities and set 0 if not. The distinction matrix of $\mathrm{I}, \mathrm{J}, \mathrm{K}$ and $\mathrm{O}$ are established by calculating the absolute difference value between indicators in average from 1979 to 2013. The data is mainly from the GILDATA, Fifty Years of Guangdong, Guangdong Statistical Yearbook and Statistical Yearbook of cities in Guangdong.

In the conventional statistical analysis such as multiple regression analysis, one of the pre-condition is that the independent variables should be independent with each other. But the relation data exists in this paper, and there may have correlation between data and have problems of multicollinearity. Therefore, it's useless to examine the correlation between variables through the conventional statistical analysis. The methods of randomization test should be used, such as QAP.

\section{QAP Correlation Analysis}

This paper chose 200000 random permutations and takes the correlation analysis between $\mathrm{R}$ and S, I, J, K and O. The following (Table 5) results show that: the difference of industrial structure will have negative impact on the spatial correlation and it implies that the greater the differences of industrial structure between cities, the more difficult the spillover effect of economic growth. The difference of economic openness degree will have positive impact on the spatial correlation. Guangdong is a province with characteristics of export-oriented economy and its GDP mainly depends on the impetus from the international market demand. Actually, regions with high degree of economic openness such as Shenzhen and Guangzhou, will always give international orders to the regions which have low degree of economic openness and weak capability of trade so that can drive their economic growth. So the difference of the economic openness degree between cities will promote the establishment of spatial correlation. In addition, the differences of wage level and fixed investment structure 
between cities just have little influence on the spillover effect. And the influence of geographical proximity on the establishment of spatial correlation is non- significant neither. This result does not conflict with the analysis above. QAP measures the situation of the whole Guangdong province. The result implies that the relation between non-adjacent cities is more than the relation between adjacent cities in the spatial correlation of economic growth. Especially when the two adjacent cities both have low level of economic development, it's hard to transfer the energy of economic growth to each other. But according to the result of Granger Causality Test above, there still has some spatial correlation between adjacent cities. After studying and analyzing, we find that Guangdong has the complete traffic infrastructure, the developed intercity traffic arteries and the extensive traffic network. It's different from the traffic between provinces in China. Therefore, the economic cooperation between provinces in China is adjacency-oriented mainly, and the economic cooperation between cities in Guangdong is different. So most of researches on spatial correlation of economic growth between provinces would prove that the spillover effect between adjacent regions is significant while is non-significant between regions in Guangdong.

Table 5. The Results of QAP

\begin{tabular}{c|c|c|c|c|c|c|c|c}
\hline $\begin{array}{c}\text { Variable } \\
\text { S }\end{array}$ & $\begin{array}{c}\text { Correlation } \\
\text { Coefficients }\end{array}$ & $\begin{array}{c}\text { Significance } \\
\text { Level }\end{array}$ & $\begin{array}{c}\text { Mean of } \\
\text { Coefficients }\end{array}$ & $\begin{array}{c}\text { Standard } \\
\text { Deviation }\end{array}$ & Min & Max & $\mathrm{P} \geq$ & $\mathrm{P} \leq$ \\
\hline $\mathrm{S}$ & 0.0408 & 0.2466 & 0.0001 & 0.0493 & -0.2081 & 0.2205 & 0.2466 & 0.8319 \\
\hline $\mathrm{I}$ & -0.0763 & 0.0677 & 0.0002 & 0.0512 & -0.2093 & 0.2076 & 0.9323 & 0.0677 \\
\hline $\mathrm{J}$ & 0.0137 & 0.3955 & 0.0001 & 0.0507 & -0.2183 & 0.2024 & 0.3955 & 0.6045 \\
\hline $\mathrm{K}$ & 0.0322 & 0.2705 & -0.0001 & 0.0520 & -0.2261 & 0.2089 & 0.2705 & 0.7295 \\
\hline $\mathrm{O}$ & 0.0991 & 0.0282 & -0.0001 & 0.0527 & -0.2414 & 0.1825 & 0.0282 & 0.9718 \\
\hline
\end{tabular}

\section{MRQAP Regression Analysis}

We chose 200000 random permutations and take the distinction matrix of industrial structure and economic openness into regression as independent variables. The spatial correlation matrix is dependent variable. The results (Table 6) further prove the QAP correlation analysis. The variables of $\mathrm{I}$ and $\mathrm{O}$ still have significant impact on $\mathrm{R}$. The standardized regression coefficient of $\mathrm{I}$ is 0.07527 and is significant at $10 \%$ level. Cities will have more common understandings and economic cooperation if the difference of industrial structure is small. Moreover, the standardized regression coefficient of $\mathrm{O}$ is 0.09831 and significant at $5 \%$ level. It's consistent with conclusion of QAP correlation analysis above too. The greater the difference of economic openness degree between cities, the more significant the spillover effect of economic growth. Regions with high degree of economic openness will always drive the economic development of regions which have low degree of economic openness and weak capability of trade.

Table 6. The Results of MRQAP

\begin{tabular}{c|c|c|c|c|c}
\hline Variables & $\begin{array}{c}\text { Unstandardized } \\
\text { Coefficients }\end{array}$ & $\begin{array}{c}\text { Standardized } \\
\text { Coefficients }\end{array}$ & P Value & Probability 1 & Probability 2 \\
\hline Intercept & 0.42082 & 0.00000 & 0.00000 & 0.00000 & 0.00000 \\
\hline $\mathrm{I}$ & -0.13770 & -0.07527 & 0.06290 & 0.93711 & 0.06290 \\
\hline $\mathrm{O}$ & 0.06017 & 0.09831 & 0.02702 & 0.02702 & 0.97299 \\
\hline
\end{tabular}

\section{Conclusion}

This paper measures the spatial correlation of regional economic growth between 20 cities in Guangdong by establishing the VAR models. We construct the spatial correlation network and 
depict the characteristics of spillover effect of regional economic growth in Guangdong based on the Analytic Network Process. The results show that:(1) The network of spatial correlation exists 160 relationships between 20 cities and the density of network is 0.421 . It implies these 20 cities are not so close in terms of economic cooperation. The connectedness and efficiency of network are 0.684 and 0.351 respectively, demonstrated that the spillover effect is stability and multiple. (2) After modularization, 20 cities can be divided into four modules: The first module is "bidirectional spillover module", including the cities of Guangzhou, Foshan and Shaoguan, which located in the active regions of economic development mainly. The second module is "net spillover module" which can transfer the energy of economic growth to peripheral areas generally, including the cities of Shenzhen, Huizhou, Shanwei, Zhongshan and Zhanjiang. The third module is "main beneficial module", including the cities ofZhuhai, Heyuan, Meizhou, Dongguan, Jiangmen and Chaozhou. The forth module is "net beneficial module", including the cities of Shantou, Yangjiang, Maoming, Zhaoqing, Qingyuan and Yunfu, and these cities are located in the western of Guangdong mostly and play the beneficiary role. (3) The network structure of spatial correlation of economic growth in Guangdong has obvious flattening feature. The second module is the main force of economic growth in Guangdong, can transfer the energy of economic growth to the first, third and fourth module generally. The first module drives the development of the second and third module. And the third module would transfer the energy to the forth module. The forth module transfers the growth energy to few cities and be the main beneficiary in the spillover effect. (4) The Pearl River Delta influences the spatial spillover of regional economic growth in peripheral areas significantly. Within the Pearl River Delta, Guangzhou and Shenzhen are the engines of the spillover effect of regional economic growth and transfer the growth energy to Foshan, Shaoguan, Dongguan and Huizhou. Then these four cities will drive other cities and promote the economic development of Guangdong finally. Zhaoqing belongs to the net beneficial module, and fails to play a role of transferring the growth energy to other cities. And Dongguan is the main beneficiary in this spillover effect. (5) The greater the differences of industrial structure between cities, the more unapparent the spillover effect. But the differences of the degree of openness between cities will promote the spillover effect of regional economic growth significantly. Cities with high degree of economic openness will drive the economic development of cities with low degree generally.

\section{Acknowledgement}

This research is financially supported by the SSF of Guangdong Province (No.2015A070704013) and Philosophy and social science project of Guangdong Province(GD15CYJ15);Guangdong key project of the integration of enterprises, universities and research institutes (NO.2009B090200062).

\section{References}

[1] J.F.Brun, J.L.Combes, M.F.Renard. Are there spillover effects between coastal and noncoastal regions in China [J].China Economic Review, 2002, 13(2-3), p161 169.

[2] Nicolaas Groenewold, Lee Guoping, Chen Anping. Regional output spillovers in China: Estimates from a VAR model [J]. Papers in Regional Science, 2007, 86(1),p101 122. 
[3] Nicolaas Groenewold, Lee Guoping, Chen Anping. Inter-regional spillovers in China: The importance of common shocks and the definition of the regions [J]. China Economic Review, 2008, 19(1), p32 52.

[4] Long Gen Ying. Measuring the spillover effects: Some Chinese evidence [J]. Papers in Regional Science, 2000, 79(1), p75 89.

[5] Li Jing, Chen Shu, Wan Guanghua, Fu Chenmei. Study on the Spatial Correlation and Explanation of Regional Economic Growth in China-Based on Analytic Network Process [J].Economic Research Journal, 2014, (11),p4 16.

[6] Pan Wenqing. Regional Linkage and the Spatial Spillover Effects on Regional Economic Growth in China [J].Economic Research Journal, 2012, (1),p54 65.

[7] ZHANG Wei-li, QIN Cheng-lin. Study on Correlation and Coordinated Development of Regional Economic Growth China [J].Economic Geography, 2010, 30 (4), p537 542.

[8] Liu Zhongli, Liu Anjun, Shao Min. An analysis on the growth spillover effect of China's Economic and Technical Development Zone and its conditions [J].Nankai Economic Studies,2010,(3),p20 34.

[9] BO Wen-guang, AN Hu-sen. Economic Operating Space of Segmented Regions in China: Based on the Analysis of Differences of Spillover Effect of Regional Growth [J].Journal of Finance and Economics, 2010, 36(3), p77 89.

[10]Long Gen Ying. Understanding China's recent growth experience:A spatial econometric perspective [J].The Annals of Regional Science, 2003, 37(4),p713 628. 